\title{
Teologie kroniek/Theology Chronicle: The Politics of Salvation: Values, Ideology and the South African National Curriculum ${ }^{1}$
}

J Jansen

(University of Pretoria)

\section{ABSTRACT \\ The Politics of Salvation: Values, Ideology and the South African National Curriculum}

The South African experience offers dramatic examples of how the curriculum remains a lightning rod for the values contestation in divided societies. Despite its overwhelming election mandate, the ruling party found that changing the curriculum required the consent of powerful and less powerful sections of society-whose opposition extended across racial lines. This essay reports on research into attempts by the post-apartheid state to introduce values explicitly into the school curriculum, and how communitiesmobilised primarily on the common front of religious valuescombined to decelerate if not reverse radical curriculum reforms. The most important finding from this work is that underestimating the power of faith-based communities is likely to undermine curriculum reforms that touch on matters of values, conscience and religious commitment.

\section{INTRODUCTION}

Like national flags and national anthems, the school curriculum has remained one of the most contested symbols of any social transition. For changing curriculum is more than fixing the modalities of teaching or learning or assessment. Especially in transition societies, curriculum change represents, in essence, a symbolic shift in the dominant values triggered by changes in political regime. Students of curriculum politics are therefore likely to encounter the wisdom once dispensed to a curriculum analyst visiting a foreign country: "show me your curriculum, and I will tell you who is in power". The problem with the South African transition, however, is that during the euphoria of the early post-apartheid period (roughly 1990-1998)

\footnotetext{
1 A much shorter and more popularised version of this article will appear in a monograph edited by Chabani Manganyi through UNISA Press (title not yet finalised) during 2004.
} 
it was difficult to read off the curriculum exactly who was in power. The reason being that there were three moments in the brief curriculum history of the new South Africa with respect to the problem of "values", only the last of which generated broad public contestation around the nature and content of the new curriculum. This presentation will describe these three curriculum moments since 1994 and how each moment dealt with the vexing problem of values in education. The narrative will demonstrate how each moment energised very different constituencies inside South Africa in opposition to the curriculum and its underpinning values. The article concludes with considered reflections on the implications of the third curriculum moment for the politics of reconciliation and the politics of curriculum in a society traumatised both by an apartheid past and a globalised present.

\section{THE FIRST CURRICULUM MOMENT: THE VALUE-BLIND CURRICULUM}

Until 1994, the broad "values" that would underpin the postapartheid curriculum (and, indeed, the education system as a whole) as identified in the early 1990s by the broad democratic movement, were: non-racism, non-sexism, democracy, equity and redress. These "principles" informed the work of the National Education Policy Investigation (NEPI) that was tasked by the National Education Coordinating Committee in the early 1990s to develop "policy options" for the broad democratic movement and, by extension, for the first democratic government that was, by this time, clearly in sight. But these value commitments were not really operationalised in curriculum terms, for there was no curriculum but a set of broad policy options that would guide decision-making once a new government took power. These values were, if anything, broad signals or symbols of change that were not at all contested for they floated free of the public school curriculum and were not translated into the kind of "content" that would redefine the substance of teaching and learning in South African schools. For the most part, the curriculum transition post-April 1994 was a peaceful one, with schools more or less doing their own thing despite some valiant attempts to apply "essential alterations" to what the new government identified as the most glaring and provocative racism and inaccuracies in the apartheid curriculum. But this activity was quite harmless, since much of the crude racism of the 1970s and 1980s 
had been quietly sanitised from the apartheid curriculum by the early 1990s.

The first curriculum moment however came with the introduction of Curriculum 2005 and its underlying methodology called "outcomes based education" (or OBE). The popular and public criticism of OBE had little to do with the social content of the new curriculum but with concerns about its impact on learning "the basics" of reading, writing and calculating. Populist writers spoke through the media of "the dumbing down" of South Africa's children under a curriculum that (it was said) had been discarded in countries like Australia ${ }^{2}$. Some academics raised implementation questions concerning the sophistication of the curriculum and its viability within third world classroom contexts (cf Jansen 1999). Most teachers, on the other hand, claimed that OBE simply represented good educational practice and, accordingly, they had been practising OBE all the time (cf Mogutu et al 1999) Whether it was practitioners, populists or professors, the criticism had very little to do with the value-content of the new curriculum and much more to do with its technical implementation and effects in the classroom. Moreover, for the majority of teachers in the country, the curriculum was welcomed as a significant antidote to the apartheid curriculum that was still fresh in the minds (and the pun is intended) of the general populace.

If anything, Curriculum 2005 was “contentless" in terms of specifications about content or values. Indeed, this position was consistent with "outcomes based education" which merely required clarity about what learners could do at the end of a period of instruction. Even the important social outcomes specified in Curriculum 2005 were of such a broad and abstract nature that a range of ideological ambitions could fill the "content" (cf Christie \& Jansen 1999).

Therefore Curriculum 2005 could be interpreted as a neutral curriculum as far as values is concerned for even though broad "critical outcomes" were stipulated, they had two limitations. One, they were not crystallised within subject matters (or learning areas)

2 Prominent among such commentators was Stephen Mulholland in his Sunday Times (South Africa) column. 
and therefore remained distant enough from the day-to-day decisionmaking in schools around matters of content. Two, as noted earlier, they were broad and abstract statements, and therefore open to a range of interpretations.

The political value of an outcomes based statement of curriculum is that it did not provoke debate and dissent about values within the broader public. Whether this was explicitly intended or not, such a position sat well with the political context of the times i.e., a spirit of reconciliation in which bringing together people together with very different social histories and community values was a very high premium for the newly elected Government of National Unity. In short, this "rainbow curriculum" signalled in broad terms the desirable value shifts in statements of critical outcomes, but there was no mechanism for translating this "down" into curriculum content in the day-to-day lives of schools.

\section{THE SECOND CURRICULUM MOMENT: CRUSADING ON VALUES IN EDUCATION}

It came as somewhat of a surprise, therefore, that the second Minister of Education since 1994 would create a specific platform on values in education. The task fell to Professor Wilmot James of the University of Cape Town to lead a team that would identify the core values around which a democratic education system would be built. True to form, the task team was "representative" of white and black, Muslim and Christian, academics and practitioners, educators and government officials and so on. In reality, the document Values, Democracy and Education was developed and composed by the Chairperson of the Committee, Professor James, with occasional comment from the Working Group. The most vociferous criticism of The Values Document, as it came to be called, was from the progressive academics, notably in the well read Quarterly Review of Education and Training at the University of the Witwatersrand. In a special issue titled The Holy State? Values, Legitimation and Ideological Closure in South African Education, Nazir Carrim and Margaret Tshoane point to the dangers of a prescriptive morality in the new political order:

The discourse of morality also implies an attempt at moderating and controlling human behaviour. It prescribes, in predetermined and undemocratic ways what 'ought' to be the case. It puts into place single, allegedly 'correct' interpretations of phenomena, since the 
discourse of morality projects itself discursively as the determiner, bearer and articulator of 'the truth'. Which cannot be questioned or debated. It expects uncritical acceptance and blind following, supposedly as an act of 'faith' and/or 'loyalty'. The discourse of morality, then, as we are currently encountering it, is antithetical to democracy, and significantly undermines the development and consolidation of a culture based on human rights ${ }^{3}$ (Author 2000:5).

I tried to capture related political dilemmas associated with the Values Document at The Saamtrek on Values, Education and Democracy (Kirstenbosch, Cape Town) convened by the Minister to launch this policy initiative. The argument is represented in full, but my main point was that even with a prescriptive set of values for schools, children learn more about values from observations of public behaviour than from the dictates of private tuition.

\section{REPRESENTATION OF THE SAAMTREK ARGUMENT}

It is unfortunate that schools have fences.

The physical and symbolic presence of a fence around a school suggests that what happens inside schools and classrooms can be separated neatly from what happens outside of them. It offers the illusion that schools are immune from society, and that our children can be sheltered from learning the harsher realities of community and public life. This, of course, is not the case, as Yizo Yizo is determined to show us. The many thousands of schools without fences in our country might in fact be the more authentic education centres, stripped of the illusion of separation between learning inside and learning outside of classrooms.

The point I wish to make is that there is a powerful social curriculum that operates in South Africa, so that what our children learn through their observations of public life is often much more important that what they might learn in school. And so I ask, what do our children learn:

- When we invade a neighbouring country by force?

- When we defame critics of social policy?

3 The Quarterly Review of Education and Training, vol 7, no 4,15 December 2000, 5. 
- When we attack ethnic communities like the Portuguese for daring to protest against crime?

- When we remain silent in the face of state brutality in Zimbabwe?

- When we deny life-prolonging drugs to mothers and children with HIV/AIDS?

What children learn from their observations about these powerful events in public life is much more enduring and formative that what they might learn about fractions in primary school or about metaphors in the language classroom. These learnings are what I refer to as a social curriculum (rather than the approved subject curriculum of the classroom) and it impacts on learners through vehicles such as television, the print media, adult conversation, radio, friends, direct observation, and many other images of life.

I raise this point because, for all our pontification about values, we behave in ways that often devastate young people and their futures.

This brings me to my assigned topic of "access" and how this might relate to the theme of the conference, namely, the role of values in education. It is useful, in the context of my argument, to distinguish two kinds of access. The first I will call physical access and the other (for want of a simpler term) epistemological access.

\section{PHYSICAL ACCESS AND SOCIAL VALUES}

It is important to acknowledge, as South Africans, that physical access remains a problem in public education. Because of high infant mortality rates and low fertility rates, fewer and fewer children enter Grade 1 than ever before. This simple fact has consequences across the education system. Because fewer children enter school, fewer graduate at the end of school (Grade 12), fewer students are therefore available to enter higher education, and fewer skilled persons are enabled to participate competently and confidently in social and economic life. I am not suggesting that low participation rates at Grade 1 represent a "natural" phenomenon. I certainly believe that physical access could be enhanced by improving the health and economic chances of families and young children, especially in relation to medication for HIV-positive mothers.

The problem of physical access to schooling is further compounded by ill-considered policies of our government, 
especially as it related to the mandatory age for entrance to Grade 1. Children can now only enter Grade 1 if they turn seven (rather than six) in the year in which they enter school. I have studied the problem of "age of entry" for many years, and in many countries, and I cannot find a single educational justification for this decision in our country. There are compelling financial justifications for this decision. But there is no educational basis for supporting this decision. This policy has severe equity implications. Given the devastation of non-governmental organisations in the years leading to and following the end of legal apartheid (1994), there are very few quality institutions supporting educare or pre-school education especially for black and rural children. The middle classes will always find ways of enhancing the pre-formal schooling of their children through such high quality (and expensive) programmes and in-house facilities such as computers, reading books and the Internet; but such opportunities are restricted by geography and finances, to a very small, mainly white, privileged elite. The nett-effect of this policy is that by the time black and white children do enter Grade 1, a year later than normal, the cognitive and emotional distance between white and black children is even greater than when they entered at the age of six years. What does this say about our values?

But we should also be honest, as South Africans, and concede that our children are not allowed to enter schools of their own choice. Throughout our country, the more privileged schools make conscious decisions to deny entry to children who fall outside of their "zones" - often marking these cut-off points arbitrarily but also consciously so that those from poor and black communities do not overwhelm the school. Some schools, such as Westville in KwaZulu Natal, have been able to remain virtually all-white, through their manipulation of these geographical cut-off points to access. More devastating, though, has been the ways in which school fees have been used to effectively rule-out access by poor, and therefore black, children from accessing the more established and privileged schools in our country. The legislation that allows schools to escalate school fees (often increasing by more than $100 \%$ in a five-year period) to such an extent that it sustains or re-creates a racial and class homogeneity in public institutions, must be re-assessed.

My point is a simple one: you do not have to tell people they do not have access (as under apartheid) to prevent them from enjoying access (as after apartheid). 
A telling example is this place where we meet.

Technically and legally, all the people of the Western Cape, irrespective of their colour, can now access these National Botanical Gardens in Kirstenbosch, Cape Town. In reality, very few people of this province can afford physical access to these beautiful facilities. All my life I grew-up around these Gardens in a struggling township called Retreat; as a young person, I could only enter once, and that was as part of a mandatory university class in Botany III - paid for by the University, and escorted by the white professor. Our family could not afford access then, and very few families can afford access now - as the ridiculous gate fees will attest. The financial barrier ensures, whether intended or not, that physical access remains limited to the few - who happen to be mainly white and well-off. Physical access, as in the case of schools, remains restricted. This discrepancy between what the law allows and what economic reality permits, is the point made so well by Neville Alexander in a question to the opening panel of this Conference.

\section{EPISTEMOLOGICAL ACCESS AND SOCIAL VALUES}

It is one thing to allow children access through the gates of a school i.e., physical access. It is quite another thing to allow young people access to knowledge - its various forms, how it is organised, its value bases, its politics, and its power. In other words, epistemological access. If we took a 'bare-faced' look at what happens inside schools and classrooms, it would become clear that with few exceptions,

- Children do not have access to life-saving knowledge about HIV/AIDS

- Children do not have access to knowledge about different cultures and languages

- Children do not have access to knowledge about the role of criticism and the value of dissent in a democracy

- Children to not have access to knowledge about care and consideration of those who are different (a critical value in the context of the AIDS pandemic)

- Children do not have knowledge about alternative ways of thinking and living 
The curriculum has, in fact, changed very little in terms of what is regarded as prized knowledge under stressful social, health and economic conditions. The labels for what we do as teachers might have changed (I am amused and concerned about the formal labelling of "subjects" among young children who do not have a clue what EMS or MML means), but the essential knowledge required is still formal, abstract, and devoid of meaning as far as everyday life is concerned. The heroes remain white, the villains black. The capitalist system remains the time-honoured way of organising economies and personal lifestyles. AIDS is a black problem, even if it does enjoy honourable mention in a South African classroom. Uniforms ensure the fact: uniformity. Children with very long hair or very short hair are both suspended, if not expelled. Muslim girls wearing traditional headgear, are suspended, if not expelled. Anything that deviates from the white, so-called Christian, middle class "norm" is ejected from the school and its mainstream culture. Alternatives are out. Children learn in English or Afrikaans in white schools; multilingualism or "additive bilingualism" are profound policy concepts that have little reality within the kinds of classrooms and schools described. And so, even though a few black children, and many white children, gain physical access to privileged schools, the reality is that all our children are denied epistemological access to the new values and the new knowledges that should accompany a new democracy.

In discussing the problems of physical and epistemological access, however, we should remind ourselves that the overwhelming majority of our children will continue to learn and live in black schools, in rural and peri-urban schools, in poor schools. It is in these contexts that the discussion about values and access need to be continued.

I wish to conclude by relating the discussion about access and values to the Conference itself.

This Conference has its origins in a Ministerial Report of the Working Group on Values in Education, called Values, Education and Democracy (Department of Education, 2000). The single most important flaw in this so-called Values Document is that it fails to locate itself within the harsh and unforgiving realities of township schooling in South Africa. Read anywhere, it is a document that would find resonance within Western culture and society. 
Its writing style, its selection of core values, and its proposed strategies for values education, fit well within a middle-class, twoparent, economically comfortable household in which noble pursuits like the origins of humanity or the fostering of literary culture, and the conduct of open debate, could be comfortably accommodated.

It does not speak to the reality of orphan- and child-headed households in which the sheer demands of survival, physically and economically, require a very different value system than that proposed by the Working Group. The dissonance between the proposed values and everyday life among South African youth was powerfully demonstrated in Salim Vally's critique of "honour" as a value: what, he asks, does this mean for gangsters who operate with their own honour code? Clearly, this was not the reference group that framed the writing of the Values document.

The "unreality" of the proposed values and strategies for achieving democratic values are also divisive. The most damaging strategy proposed is "a pledge of allegiance or vow at weekly school assemblies [that] will serve as a reminder of the fundamental values to which South Africans in a democracy aspire" (page 50 of the Values Document). If formally adopted by the Ministry of Education, our children will be required to pledge the following (extract):

"I promise to be loyal to my country, South Africa, and to do my best to promote the welfare and the well-being of all of its citizens..."

There are two problems here, the one of loyalty and the other of national identity. The quest for national identity, if pursued in this way, can be very divisive in the reality of South African schools. Consider two schools: one in Brooklyn, Pretoria and the other in Clermont, KwaZulu Natal. The Brooklyn School is a middle-class school that attracts large numbers of children from the "embassy families" in Pretoria. About $30 \%$ or more of the children in any classroom could be from the rest of Africa, Europe, Asia, Latin America and so on. Imagine these children are part of a school assembly sitting in which the pledge is recited. As with the case of using school assemblies as church functions when there are Muslim or Hindu children present (or segregated), the use of assemblies as places to recite oaths that alienate children from other nationals can be very divisive and destructive to institutional values. The Clermont 
school is a lower income school that attracts large numbers of children from Mozambique along the border of the province (whether these children are there legally or illegally is less interesting). Imagine the children of this school gathered in assembly amongst scores of children from a neighbouring country whose citizens are regarded as threats to the pavement economies of the major urban areas in South Africa. The recitation of an oath will do nothing else than to deepen animosity and xenophobia, twin scourges faced everyday within our communities, inside and outside schools.

But the elite, abstracted, high-culture goals of the Values document are also reflected in the setting and products of this Conference. The glossy, impressively packaged Values document itself must surely be a multi-million Rand production, which, for reasons of cost alone, could never reach all our schools. Which probably explains why, of all the invited responses to the document, only three came from our 29,000 schools.

The physical location of the Conference, as suggested earlier, is itself a poor reflection on our sense of values. This very expensive setting, to which a minority of provincial residents have access, is not the place to convene a conference on values. The hosting of the Conference itself can be expected to be a multi-million Rand exercise. There is, in my view, a disjunction between what the conference is about, who it is about, and what it hopes to achieve, and the elaborate, first world, expensive setting and products to emerge from this Values event.

And so I conclude: in what ways are we complicit in sustaining the very inequalities which give rise to our warped values, and to which Edward Said (in questions to the opening panel of the Conference) so eloquently referred?

But while the critical reaction to the Values Document came largely from a small group of progressive academics, the reaction to the subsequent National Curriculum Statement emerged mainly from the large Christian Right constituency and, in particular, from a vociferous group of 'home-schoolers' in South Africa. This latter reaction is what I describe under the third curriculum moment in South African education history since the mid-1990s. 


\section{THE THIRD MOMENT: THE CURRICULUM FROM HELL?}

Shortly after his appointment in 1999, the second Minister of Education hinted that a review of Curriculum 2005, the flagship project of his Department in the first four years of democracy, would be undertaken. In the words of Kader Asmal:

"While giving unreserved support to the approach, the Ministry of Education will resist over-zealous attempts from any quarter to convert OBE into a new orthodoxy with scriptural authority. There will be no mystification of an approach to learning and teaching that is essentially liberatory and creative. I have directed that the Department of Education undertake a speedy review of the implementation of outcomes based education, with a view to the phasing of the introduction of new grades" (Asmal 1999:12).

With these commitments in mind, a Review Committee on Curriculum 2005 was convened and reported back with a report titled A New Curriculum for the $21^{\text {st }}$ Century ${ }^{4}$. In a critical paragraph on "What is to be Taught", the Review Committee made the following important observation:

Curricular content is by its nature never neutral. It is always connected to a social project. This does not mean that its specification should be avoided, however. What it means is that we should be as clear as possible about the social project to be supported. This report is predicated on a curriculum based on the values of social justice, equity and development; one that seeks to foster the values of human rights, anti-racism and anti-sexism, relevance, critical thinking and problem solving. It is to a curriculum content for these values that we now turn ${ }^{5}$.

This was the closest any official document had come to correcting the "contentless" nature of the original OBE-based curriculum, and giving expression to the more specific statement of values signalled

4 A South African Curriculum for the Twenty First Century: Report of the Review Committee on Curriculum 2005, Presented to the Minister of Education, Pretoria, 31 May 2000.

5 Ibid., 48 (downloaded version). 
within the Values in Education discussion document. It was also a moment that launched South Africa into perhaps the most intensive and sustained curriculum debate from a relatively dormant constituency i.e., the Christian Right. But the Review Committee Report would probably have passed harmlessly into oblivion (like the values signalled in the original NEPI Reports) had a subsequent "task team" not taken on the assignment of translating this vision into what was called a National Curriculum Statement for Grades R9. The NCS was in turn translated into substantive content in eight learning areas, each with its own publication (book, about 100 plus pages each) that contained learning outcomes and assessment standards for each Phase of compulsory schooling.

To understand the response of the Christian Right, it is perhaps useful to identify the kinds of political catalysts in the National Curriculum Statement that would provoke such a movement inside South Africa. Most of the contentions lie within the Social Sciences and the Life Orientation learning areas.

The assessment standards for Grade $\mathrm{R}$ requires that the learner

- names the part of his/her body, indicates those which are private, and recognises inappropriate touching (p.20);

- identifies at least 3 symbols linked to the belief systems of their families (eg rosary, cross, pictures of mosques, goddess, water pot, nature);

The assessment standards for Grade 1 requires that the learner

- identifies at least 3 people to report inappropriate touching to (p.24);

- explains the cause and prevention of at least 2 contagious, infectious and transmitted diseases (including HIV) - p.25;

- identifies symbols linked to his/her own belief system and at least 3 other belief systems in South Africa (p.26).

The assessment standards for Grade 3 requires that the learner

- describes at least 3 different ways that people worship (p.27). 
For Grades 4-6 teachers are told that "this phase includes both sexually active and inactive learners - you need to handle these differences with care when introducing associated risks” (p.34).

Grade 5 learners should be able to "describe and compare a festival, ritual or custom from at least four belief systems in South Africa" (p.39), and "participate in or plan the local celebration of at least 1 national day (e.g. Youth Day, Human Rights Day, Freedom Day, National Women's Day) - p.39; and "discuss the significance of sacred space in at least 4 belief systems in South Africa” (p.39).

In the Senior phase (Grades 7-9), learners "should participate actively in civic and human rights programmes, and through these gain knowledge of a range of systems dealing with life cycles and associated values" (p.46). They should also "explain what to do to prevent the spread of sexually transmitted diseases (including HIV) in at least 3 situations (eg casual dating, steady relationship, rape) p.50. They "discuss the celebration of life cycles in South Africa by at least 4 cultural groups” (p.52); “describe at least 6 factors which influence self-concept (e.g., gender, racial biases, economic status....” (p.55).

More could be said, but this brief overview of the valuedirectedness of the revised curriculum will place the reading of the public response, and particularly that of the Christian Right, in perspective.

This curriculum is historical in the sense that it generated the most sustained and intense onslaught against the curriculum, and from a relatively dormant community in educational termsChristians. The form and content of the hundreds of "letters to the editor" suggest that this campaign was orchestrated, and that its origins lie with the Pretoria-based Pestalozzi Trust Home Schooling movement, established in 1998. In a pamphlet titled New National Curriculum: Assault on Religion, Family and Democracy, the group issued a call to its constituency to flood newspapers, politicians, the Minister of Education and "church or faith community" to voice concerns about the following (quotations more or less direct, except for verb adjustments):

- the relentless programme of psychological conditioning; assaulting the psychological integrity of children, rendering them vulnerable to propaganda 
- the imposition of the Interfaith religion as a compulsory, examinable subject, requiring children to confess the values of this religion if they want to receive recognised qualifications

- the establishment of a norm of "group think", demonising minorities, individual freedom and enterprise, obliterating the individual identity of children under the crushing weight of the collective

- the destruction of social and cultural diversity by homogenising all cultural and moral values and requiring children to demonstrate state approved values to receive qualifications.

In addition, people should insist that:

- the state has no mandate to impose any values except one: abidance by the Law

- the teaching of religious and cultural values must be taught in schools according to the wishes of the children and their families

- the governing body of each state school must approve all values taught in the school, and specifically the subjects Social Sciences and Life Orientation

- the governing bodies must select the textbooks and supervise assessment of all values in the school.

And concluding, the readers are charged to "Ask them, in your covering letter, what steps they plan to take to protect the individual, religious and cultural rights of children and families”.

The letters flowed.

The United Christian Ministries, quoted through its spokesperson, Tumi Tlale, in a one-page letter dated 3 October 2001, was perhaps the most aggressive in its position and questioned the credibility of politicians and the state itself:

"We will be calling upon all our affiliate organisations and members nationwide, to declare the state an enemy of the Church and to treat it as such.... The proposed curriculum is a gross insult to both Christians and to the freedoms expressed in our constitution.... It is a sign of a 
corrupted tyranny when supposed leaders of our people would force a Christian majority to learn and accept evolution, ritual medicine, paganist earth worship and consider it failure if students do not subscribe to these values... We call upon all Christians to withdraw their vote from the ANC and those within the ranks to resign out of good conscience".

Colleen Watney of Nahoon, East London, was more restrained in her complaint, pointing to the constitutional protection of freedoms. In her words,

"Yes, South Africa has diversity in all its cultures, but I do not believe that your department can prescribe on the areas of religion to be taught to learners, as this infringes on their rights of freedom of religion and association. It also imposes on their freedom of expression, especially if they are being assessed on their knowledge and 'tolerance' to other religions and cultures (Daily Dispatch, 13 October 2001).

In the same vein, J C Neilsen of Germiston complains about the constitutional violations implied in the new curriculum:

"I feel very strongly that it should not go forward in its current state as it repeatedly violates the constitutional rights of the individual. For example, I believe that the right to choose religious beliefs is fundamental, and must be protected by the constitution. As a parent, I am responsible to God for my children's education, and I disagree strongly on many points in the curriculum" (Citizen, 15 October 2001).

But Rob McCaffery, an educator from Cape Town, is more concerned about the scope of the curriculum i.e., the extension of the curriculum to all schools, not only public institutions:

"As an educator, I am concerned about the approach to education that the ANC government is pursuing through the new national curriculum. The new curriculum is intended to be implemented in every school across South Africa, regardless of province or whether the school is public, private or home-school. Because the government is setting the curriculum, and setting the one nationwide 
matric exam too, there is no independence within the system, no checks and balances. This paves the way for tyranny, State controlled propaganda and social engineering... The government should give parents and the communities the freedom to choose between different types of education” (Pretoria News, 15 October 2001).

The failure to break with the past concerned Nicki Blakeway of Empangeni:

"The history curriculum is basically a biased, politically motivated agenda no better than its apartheid predecessor. It dwells on divisive differences and contrasts. Great amounts of relevant history are forsaken for endless discussion on apartheid.... Values, beliefs and views are the lead stars in this drama, all of which have no business in schools unless one wants to follow the example of the Nazi regime” (Mercury, 1 October 2001).

The letters continued to flow.

In November 2001 "public hearings" were held on the NCS under the oversight of the Parliamentary Portfolio Committee on Education. The stormy interactions between the Christian Right and the Minister with his departmental officials confirmed the high stakes at play in the NCS with respect to values and the Christian Right. Detailed submissions were made. By the end of the year, the Life Skills Statement was under review and the writing teams "reassembled" to revise the NCS in the light of the submissions received from the public. It is highly likely that the Department of Education will reduce or even eliminate the contentious areas of the curriculum (especially as far as the social sciences and life skills curriculum statements are concerned); alternatively - as initial redrafts of the National Curriculum Statement suggest - the Department could fall back on ambiguity and abstraction as guiding curriculum principles, leaving the statements open to flexible interpretation among teachers.

\section{THE UNRESOLVED QUESTIONS IN THE DEBATE ON VALUES}

In reviewing these three curriculum moments, I now wish to state my main thesis. During the early transition period from apartheid, the state had effectively suspended action on translating its broad 
and agreeable value commitments into curriculum reality in South African schools. In this period of early transition (arguably, 19901999), the politics of reconciliation dominated social and educational spheres as the country sought an uneasy accommodation between the old and the new, between entrenched conservative values and the progressive values underpinned in the South African Constitution. During the later transition period (2000-), the state gradually assumed a more strident approach to the values question in education, this approach neatly captured in the 2001 release of the National Curriculum Statement. This movement from the political accommodation of diverse values to the political assertion of preferred values in education and society, created the most intense public challenge to state education since the introduction of Bantu Education (and its ethnic variants) in the 1950s.

However, this assertion of official values into the school curriculum is likely to witness a retreat on the part of government in the face of a public revolt. There is a precedent for curriculum retreat in the region. In 1989 the self-proclaimed socialist government of Zimbabwe decided to introduce an explicitly socialist curriculum called the Political Economy of Zimbabwe - into its public schools. Within weeks, the curriculum was recalled following intense public protest, again led by the Churches, against what was perceived to be an atheistic curriculum that departed from the dominant values of that society (Jansen 1991:76-91). What does this mean? Quite simply, the fact that an anti-colonial liberation struggle was fought on grounds of political radicalism does not mean that a post-colonial curriculum can be installed on the grounds of radical social values. This is the crucial lesson to be learned from both the Zimbabwean experience with Political Economy and the South African experience with the National Curriculum Statement. Both curricula revealed insightful trends within the social order that I wish to state as tentative propositions on the church, politics and the public school curriculum.

First, that the conservative Christian core of both societies remained undisturbed despite years of liberation struggle; the dominance of radical politics in the liberation movement inside (South Africa) and outside (Zimbabwe) the settler colonial state did not translate into the transformation of important social institutions such as the Church and, especially, the conservative churches. Second, that conservative Christian communities that remained 
relatively dormant throughout years of political struggle, can be mobilised into action when official values - such as concretised in curriculum statements - are perceived to fly in the face of dominant social values.

Third, that the irony of new democracies is that the very space created by post-colonial society for democratic practices provoke into action those elements (such as the conservative churches) that through silence or complicity played a subdued role under white rule. Fourth, that the conservative Christian response to the public curriculum is not describable in racially exclusive terms i.e., the spectrum of responses covers both traditional white and conservative black churches. It is not easy, therefore, for government to dismiss this constituency simply on the grounds of being reactionary racists.

But however one characterises the nature of the opposition to the state curriculum, this response by the churches raise critical issues that percolate in curriculum theory and practice throughout a world that is being reshaped by globalisation, resulting in the creation of new national entities (as in Eastern Europe), new immigrant flows (as in Scandinavia) and new social identities (as in Australia). One of the most difficult curriculum questions in this regard is whether $a$ public school curriculum in a multicultural society can in fact achieve inclusion. A recent issue of Pedagogy, Culture and Society $(2001)^{6}$ debates this question at length, using comparative experiences from Europe, North America and Scandinavian countries. The evidence is ambiguous at best, because any attempt at specification of values invariably some group or identity out of the curriculum equation.

But my sense is that the opposition in South Africa is not galvanised by feelings of exclusion; rather, it is the loss of privilege, the erosion of a long-standing dominance of Christian values in the public school curriculum that lies at the root of the awakening of the Christian Right. The selections drawn from the NCS clearly demonstrate that Christian symbols, values and experiences remain an important component of the curriculum; it is the fact that in addition, schools will have to draw on exemplars, symbols and experiences of non-Christian communities that concern conservative

6 See volume 9, number 3 of Pedagogy, Culture and Society, Special Issue: Curriculum and the National Question, Edited by David Hamilton. 
Christian communities. It is not therefore the fact that this curriculum is less explicit about values that should concern the curriculum analyst; rather, it is the fact that the kind of values that the curriculum is explicit about is unacceptable to the conservative Churches.

But the Values Debate also raises the perennial curriculum concern of specification. Clearly the problem of values was not a political contest when such values were only articulated at the level of broad visions for education (such as the NEPI experience) or in the form of generic outcomes (such as the initial C2005 version). Values became contested in the public domain once such values became concretised in the "syllabuses" of the National Curriculum Statement booklets. In the Swedish context, the "concretisation" was largely the responsibility of teachers as they translated abstract values into real classroom applications (Norberg 2001:371-386). But can teachers be trusted with translating such broad statements into similar patterns of meaning for an emerging democracy? Can white teachers in a former white school in a conservative community be trusted with conveying the kinds of values that signify the new demands of a changing democracy? Here lies the dilemma: specification of what should happen in classrooms at the local level might create tighter conditions for teacher behaviours but that very specification creates the kind of political reaction demonstrated in the various public comments. Furthermore, the problem with specification is how much specification is enough? There is evidence from curriculum research to show that even when teachers in the same national context are provided with the same curriculum specifications, they translate such specifications into very different meanings based on who they are and also where they are in a specific school locale (Olneck 2001:333-354). The problem might, in fact, be less of a curriculum design concern and more of a curriculum politics issue. For while specification might yield political assurance that official values are being taught in schools, it might not be achieved anyway because of the many filters through which official values pass, and are transformed, on the long route to children's heart and minds. The state might resort, at the end of this process, to recognising the value of ambiguity in curriculum policy while still being able to claim that official values have been proclaimed. 
What is even more perplexing in this curriculum stance - that is, one that makes official values explicit for the classroom level - is the fact that the NCS targets learners and not teachers. What learners should be able to do (in terms of values) clearly cannot be accomplished without some specification of how teachers are to change or transform in terms of their own value commitments. This is especially crucial if teachers are regarded as the final filter through which official values are translated into the classroom (Norberg 2001:371-386). If this position is taken seriously, the values debate as a learner-focused event could be regarded as a distraction, given the very disparate values of teachers and their professional identities (Jansen 2001:242-246) and how such divergence in the value bases of teachers influence the curriculum. South African teachers are adults who have very different historical, economic, political and religious experiences. Their values remain a challenge to "the inner life of schools” (Norberg 2001:371-386). Thus, if implementation is in question, the lack of strategy for transforming teacher values may be more important that transforming learner values (Norberg 2001:371-386; Olneck 2001:333-354).

\section{ON THE POLITICS OF SALVATION AND THE NATIONAL CURRICULUM}

What September $11^{\text {th }}$ means for curriculum and politics is, in one sense, quite simple: our failure to create the means for inter-faith dialogue and understanding could, quite literally, destroy us. In another sense, the challenge is formidable. On adjoining walls outside a revamped Athlone sports stadium in Cape Town I found, last week, a fascinating reminder of the realities of this struggle on local turf. One wall hailed Jesus; the other, PAGAD (a radical Muslim-based movement). The distinguished Ugandan scholar, Mahmood Mamdani, placed his finger on the heart of the problem: in two messianic faiths, each seeking to convert the other, the search for common ground will be difficult. And it is the nature of faith, and its rooted values, that the writers of the NCS made the crucial error of misunderstanding. For to bring together faiths whose fundamental beliefs are based on a caricature of the other, whose central doctrines are interpreted among fundamentalists on both sides to mean the demonisation of the other (witness the response of Franklin Graham to September $11^{\text {th }}$ ), requires more than a listing of preferred values or sequencing of topics on faith and religion. It requires a curriculum and pedagogy that fosters genuine and 
sustained dialogue within and outside schools on faith, commitment, respect and understanding. It requires demonstration of the fact that learning to respect other faiths could be done in a way leads to a deepening of one's own faith commitments and a broadening of one's faith horizons (Charaniya \& Walsh 2001). And it requires, most of all, a clear understanding of consequences: that dogmatism and demonised depictions of those who are different have no basis in a human rights culture and could, quite literally, destroy civilisations. Such a task can only be undermined by a superficial approach to the values question. It is in this sense - and in this sense only - that the Christian response to the NCS might have pre-empted "ideological closure" (Carrim \& Tshoane 2001:7) on a debate that has yet to happen in schools as well as in society.

\section{Consulted literature}

Asmal, K 1999. Call to Action: Mobilizing citizens to build a South African Education and Training System for the $21^{\text {st }}$ century, Tuesday 27 July 1999:12.

Carrim, N \& Tshoane, M 2001. The Holy State? Values, Legitimation and Ideological Closure in South African Education. Quarterly Review of Education and Training, University of the Witwatersrand, Special Issue, 7.

Charaniya, N K \& West Walsh, J 2001. Interpreting the Experiences of Christians, Muslims and Jews Engaged in Interreligious Dialogue: A collaborative research study. Religious Education 96(3).

Christie, P \& Jansen, J D 1999. Changing Curriculum: Studies in Outcomes Based Education in South Africa. Cape Town: Juta Academic Press.

Jansen, J D 1991. The State and Curriculum in the transition to Socialism: The Zimbabwean Experience. Comparative Education Review 35(1), 76-91.

-, 1999. Why outcomes Based Education Will Fail: An Elaboration in: Jansen, J \& Christie, P (eds). Changing Curriculum: Studies in outcomes based Education in South Africa, Cape Town: Juta Academic Press.

-, 2001. Imagening Teachers: Policy Images and teacher identity in South African Classrooms. South African Journal of Education 21(4), 242-246.

Maqutu, T et al. 1999. A Very Noisy OBE: The implementation of Outcomes Based Education in Grade 1 classrooms. The Centre for Education Research, Evaluation and Policy. University of Durban Westville.

Norberg, K 2001. The Constitutive Values of Swedish Schooling: a challenge to the inner life of schools. Pedagogy. Culture and Society 9(3), 371-386

Olneck, M R 2001. Re-naming, Re-imagining America: Multicultural curriculum as classification struggle. Pedagogy, Culture and Society 9(3), 333-354 


\section{Newspapers and reports:}

A South African Curriculum for the Twenty First Century: Report of the Review Committee on Curriculum 2005, Presented to the Minister of Education, Pretoria, 31 May 2000.

Citizen, Monday 15 October 2001. The author of this article strongly object to the New National Curriculum.

Daily Dispatch, Saturday 13 October 2001.

Mercury, 1 October 2001. The Current Curriculum is just as Biased as the Old.

Pretoria News, Monday 15 October 2001. Concerns about education.

The Quarterly Review of Education and Training, 7/4, 15 December 2000. 